\title{
La falsa erudición en la Ilustración española y novohispana: Lizardi
}

\author{
The false erudition in the Spanish and Mexican \\ Enlightenment: Lizardi
}

\section{Mariela Insúa}

\author{
Universidad de Navarra, Grupo de Investigación Siglo de Oro (GRISO), Navarra, España. \\ Correo electrónico: minsua@unav.es
}

Este artículo ofrece una aproximación a la figura del hombre de letras en la Ilustración española y novohispana. Se centra especialmente en el tema de la falsa erudición en la obra periodística y literaria del mexicano José Joaquín Fernández de Lizardi (1776-1827).

Palabras clave: ilustración, hombre de letras, falsa erudición, Fernández de Lizardi, periodismo mexicano (siglo XIX).

This article offers an approach to the figure of man of letters in the Spanish and Colonial Mexican Enlightenment. It focuses especially on the issue of false erudition in the journalistic and literary work of the Mexican José Joaquín Fernández de Lizardi (1776-1827).

Key words: enlightenment, man of letters, false erudition, Fernández de Lizardi, Mexican Journalism (XIX century).

\section{INTRODUCCIÓN}

Con el advenimiento de la Ilustración, el paradigma de rasgos que acompañan al modelo del sabio experimenta un cambio notable con respecto al período barroco anterior. En primer lugar, la preocupación de los sabios ilustrados, o de aquellos que pretenden serlo, pasa a girar en torno a una dicotomía básica: la verdadera sabiduría en oposición a la falsa. Podría decirse que todas las reflexiones acerca del saber y sus distintos agentes y manifestaciones rozan, en algún sentido, esta oposición. Así, por ejemplo, en el ámbito español, un autor tan destacado como Benito Jerónimo Feijoo dedica el discurso octavo del tomo segundo de su Teatro crítico universal (1724-1739) a diferenciar la "sabiduría aparente" de aquella que puede valorarse como auténtica. El benedictino señala que la hipocresía en el saber constituye una de las peores lacras de su tiempo y que puede afectar al desarrollo del recto curso de las naciones. A continuación, indica que engañar al vulgo con fingimientos resulta fácil: bastan "la eficacia del ademán y el estrépito de la voz", la apariencia grave y 
circunspecta, la "oscuridad" del discurso, en suma, un simple "parecer" sabio, para que los ignorantes aplaudan. Entre esa caterva de sabios engañadores descritos por Feijoo sobresalen aquellos que atraen la atención del público no por su sapiencia, sino por la exageración al moverse:

Ya se arruga la frente, ya se acercan una a otra las cejas, ya se ladean los ojos, ya se arrollan las mejillas, ya se extiende el labio inferior en forma de copa penada, ya se bambanea con movimientos vibratorios la cabeza, y en todo se procura afectar un ceño desdeñoso. Estos son unos hombres que más de la mitad de su sabiduría la tienen en los músculos, de que se sirven para darse todos estos movimientos (Feijoo 1983a: 79).

En el polo opuesto de estos teatreros del saber ubica Feijoo a los auténticos sabios, caracterizados por su modestia y candidez. Estas dos virtudes, según el fraile gallego, suelen afectar de modo negativo a la fama de los doctos pues muchas veces, al decir grandes verdades con palabras sencillas y sin rimbombancia, no son valorados por el auditorio escaso de luces. Añade además que la agudeza no se consigue únicamente con el estudio, y que es preciso estar dotado de entendimiento: si no se tiene, poco ha de lograrse con la memorización desnuda de inteligencia. Estas ideas son ampliadas por Feijoo en un discurso titulado "Dictado de las aulas" (tomo octavo, discurso tercero) en el que completa los citados postulados con referencias a la oratoria; ahí critica la retahíla de silogismos de que suelen abusar los malos oradores y propone que se fiscalice la calidad de los profesores en las universidades (1863b: 438-41).

Mas, sin duda, el tratamiento de la oratoria sagrada que peca de afectada tiene su máxima materialización literaria en la novela del Padre Isla Historia del famoso predicador Fray Gerundio de Campazas (1758-1770), obra en la que el jesuita realiza una sátira de los sermones barrocos, culteranistas y extravagantes, poblados de complejas alegorías de predicadores al estilo de Fray Hortensio Félix Paravicino. Dentro del complejo de rasgos antimodélicos del hombre de letras ilustrado, el "gerundianismo" ocupa un lugar destacado. La sátira de este tipo de predicación sagrada coincide con la crítica emprendida por varias plumas del Siglo de las Luces que propugnarán, en distintas áreas, un discurso claro y efectivo en oposición a vacíos alambiques retóricos.

Dentro de este panorama de la conceptualización de la sabiduría en la época ilustrada, no podemos dejar fuera las consideraciones a este respecto expuestas por José de Cadalso, especialmente en sus Cartas marruecas (1789). Esta obra es heredera, desde el punto de vista genérico, de las Cartas persas (1721) de Montesquieu. Cabe señalar que en las epístolas del francés también el saber era objeto de tratamiento, especialmente el tema del academicismo vacuo. Encontramos así alusiones a los vanidosos sabios parisinos como la planteada por Usbek a su amigo Rica en la carta 144:

Pocos días hace que hallé en una quinta dos sabios que aquí son muy célebres, me parecieron de maravillosa índole. La conversación del uno se reducía a esto: lo que he dicho es ciertísimo porque lo digo yo. La del segundo significaba esto otro: lo que no he dicho es falso porque no lo digo yo (Montesquieu 2000: 279-80).

La reflexión de Cadalso se encuentra enmarcada por los postulados ilustrados acerca del sabio, del philosophe, como hombre honrado (honnête homme), volcado 
al conocimiento pero también a los prójimos, "que une a un espíritu de reflexión y precisión las maneras y los rasgos de la sociabilidad" (Sebold 1974: 204). En varios pasajes de las Cartas marruecas se refleja esta intención de reflexionar acerca del cambio en el paradigma de rasgos que han de caracterizar a un docto, el cual tendrá que comportarse ante todo como un hombre de bien. Así lo expresa el maestro BenBeley en carta a su discípulo Gazel:

Sí, Gazel, el día que el género humano conozca que su verdadera gloria y ciencia consistía en la virtud, mirarán los hombres con tedio a los que tanto les pasman ahora. Estos Aquiles, Ciros, Alejandros y otros héroes de armas y los iguales en letras dejarán de ser repetidos con frecuencia; y los sabios (que entonces merecerán este nombre) andarán indagando a costa de muchos desvelos los nombres de los que cultivan las virtudes que hacen al hombre feliz (Cadalso 2002: 223-24).

Otro elemento destacable en la propuesta cadalsiana es su apertura en la consideración de la relación del sabio con su contexto en tanto lo muestra afable, inmerso en la sociedad y acogiendo las novedades del conocimiento, lo que se opone al comportamiento del adusto sabio tradicional -"muy seco, muy alto, muy lleno de tabaco, muy cargado de anteojos, muy incapaz de bajar la cabeza ni saludar a alma viviente" (Cadalso 2002: 331)-, que rechaza la poesía, las matemáticas modernas, la física y los adelantos de la medicina.

Como se puede apreciar, durante la Ilustración se gesta un nuevo tipo de intelectual: un "hombre de letras" erudito pero no retraído en su gabinete, sino que participa en la lucha de las ideas en el ámbito de la colectividad. Cabe señalar además que muchas veces el letrado hace compatible su labor erudita con la experimentación directa. Es más, en varios autores de la época la experiencia se erige como el valor fundamental para el conocimiento. Un ejemplo paradigmático de esta cuestión lo constituye el célebre discurso "El gran magisterio de la experiencia" de Feijoo, en el que el benedictino presenta a dos entidades alegóricas, Solidina (la experiencia) e Idearia (la imaginación), que llegan al reino de Cosmosia (el mundo) con el fin de dominar a sus habitantes mediante la educación. La primera, charlatana y presuntuosa, los engaña y les dice que los hará a todos doctos en poco tiempo; en cambio, la sencilla Solidina se aboca a entregarles enseñanzas prácticas, verdaderas y útiles. Esta última sale victoriosa, pues convence a todos los pobladores con máximas comprobables y demostraciones palpables (Feijoo 1986: 332-35).

Finalmente, importa señalar que, tal como veremos más adelante, este nuevo modelo del saber tendrá que convivir, además de con sus pares, miembros de la República de las Letras, con otros agentes difusores de cultura y novedades: con escritores considerados "más comerciales", como los periodistas, los cuales desarrollaban su actividad en estrecho vínculo con la naciente opinión pública.

\section{EL hOMBRE DE LETRAS EN LA ILUSTRACIÓN}

Se considera que la primera obra explícitamente dedicada al hombre de letras es L'uomo di lettere (1645) del jesuita Daniello Bartoli; en ella se ofrece la imagen de 
un sabio al servicio de Dios. Este texto contará con gran difusión en el siglo XVII ${ }^{1}$ y será varias veces reeditado en el siglo siguiente. La recuperación en el contexto dieciochesco puede entenderse si se tiene en cuenta la polémica que tendrá lugar en este período entre los sabios tradicionales y los nuevos escritores.

Voltaire define al hombre de letras en la entrada "Gens de Lettres" de la Enciclopedia haciendo referencia a su capacidad para abarcar un saber amplio: "no se da ese nombre a alguien que, por poseer pocos conocimientos, cultive un solo género" (Cit. en Chartier 1995: 153). De este modo, el hombre de letras, pariente ilustrado del sabio humanista, es inscrito, en el complejo del enciclopedismo, como un intelectual que maneja nociones de distintas disciplinas, pero sin profundizar en ninguna materia en particular. Tal como señala Chartier, el devenir del erudito humanista -encarnado fundamentalmente en el filólogo como fuente de todos los saberes- hacia la figura del hombre de letras ilustrado está marcado por el paso de un conocimiento asentado en la crítica gramatical a otro respaldado por un "espíritu filosófico" (Chartier 1995: 154). Por otro lado, Voltaire entrega en sus distintos escritos, especialmente en sus Cartas filosóficas (1734) y en el Diccionario filosófico (1764), reflexiones acerca del quehacer de los pensadores y estudiosos en un momento en el que se va notando falta de interés por parte de la sociedad hacia temas relacionados con la cultura. Otro aspecto importante abordado por el filósofo francés es el de la indefensión del hombre de letras en su siglo, provocada por las habladurías y la inquina que los letrados se guardaban entre sí (Álvarez Barrientos 1989: 417-18).

Una obra de temática similar publicada en torno a estos años es L'Homme de Lettres (1764) de Jean-Jacques Garnier. En ella se define al hombre de letras como "aquel cuya principal dedicación consiste en cultivar su espíritu por el estudio para hacerse mejor y más útil a la sociedad" (Cit. en Chartier 1995: 182). Este último énfasis en la utilidad cuadra perfectamente con la preocupación práctica de los ilustrados. Sin embargo, Garnier no aboga por el tipo del letrado de salón entregado a la banalidad; por el contrario, considera que el estudioso ha de concentrarse en sus labores alejado de los estímulos del mundo.

Cabe aclarar en este punto que los cultivadores del saber fueron llamados de diferentes formas durante este período. Así, en el ámbito ilustrado español se utilizaban los términos literato, escritor y hombre de letras para designar a aquellos que escribían. La denominación hombre de letras, si bien no es recogida por el Diccionario de Autoridades, sí está consignada en el Diccionario castellano de Esteban Terreros y Pando con el significado de «letrado o sabio». Asimismo, tal como indica Álvarez Barrientos (1995: 25), aparece también en la introducción al Diario de los literatos de España en 1737. Por otro lado, durante el siglo XVIII los marbetes hombre de letras y literato fueron utilizados como sinónimos, mientras que la denominación erudito poseía una connotación negativa, vinculada en algunos casos a los tachados de meros charlatanes o violetos. Es importante acotar también que el término literatura en el siglo

\footnotetext{
1 Reimpreso ocho veces el mismo año de su publicación, traducido al francés en 1654, cuenta con diecinueve ediciones en italiano entre 1654 y 1689; fue además traducido al inglés (1669), al alemán (1677), al español (1678) y al latín (1693); en el siglo XVIII, es recuperado a través de una nueva traducción a cargo del Padre Dalivoy bajo el título L'Homme de lettres (1779), y en España será reeditado dos veces en la nueva centuria (1744 y 1786). Mayores datos en Chartier 1995: 182; y en Álvarez Barrientos 1995: 25.
} 
XVIII poseía un significado mucho más amplio que el que le damos hoy; por ello se consideraba que el literato era aquel que se ocupaba de las letras, incluyéndose en este grupo a los poetas y a los dramaturgos, pero también a los sujetos que se vinculaban con el saber y con el estudio en general (Álvarez Barrientos 1992: 13).

He señalado que uno de los aspectos centrales en esta transformación del modelo del sabio en el período ilustrado radica en su apertura a la sociedad. Esto se verá reflejado en la necesidad del hombre de letras de comunicar sus saberes en círculos amplios, no circunscritos exclusivamente a sus iguales, sino muchas veces abiertos a un auditorio variopinto que incluye a miembros de la burguesía. Es más, se podría afirmar que el gran cambio en el paradigma de rasgos del modelo del letrado en la Ilustración se ubica en el nuevo modo de relacionarse con los otros, es decir, con sus pares y con un público amplio.

A diferencia de los sabios del Humanismo, generalmente vinculados a la Iglesia o a casas nobles y que por tanto no vivían directamente de la recepción de sus obras, los hombres de letras dieciochescos comienzan a requerir lectores que les compren sus obras para poder mantenerse. Esta circunstancia trae aparejada un rotundo cambio en el desarrollo de la actividad intelectual. Por ello el asunto de la subsistencia del escritor es una preocupación recurrente en varios intelectuales de la época. El mismo Voltaire reflexiona acerca de este tema y aconseja que lo óptimo para el letrado es no depender de su escritura para vivir, pues esto podría afectar a su libertad a la hora de pronunciarse sobre determinadas materias (Cit. en Chartier 1995: 156). Esta cuestión intuida por Voltaire es lo que, al fin y al cabo, genera la encrucijada en la que se ha de situar el hombre de letras a partir del Siglo de las Luces: la de procurar compatibilizar el ejercicio intelectual y el negocio.

Ante este matiz "mercantil" que comienzan a adquirir la cultura y su difusión, los miembros más conservadores y elitistas de la República de las Letras asumirán una postura negativa, de rechazo frente a esos nuevos "escritorzuelos" y periodistas que veían en la escritura un modus vivendi y luchaban por captar la atención del público. Es éste el momento en el que, tal como planteaba López de Sedano en El Belianís literario (1765), las letras comienzan a considerarse como un bien "de cambio" (ver Álvarez Barrientos, 1993). La vinculación de este ingrediente "comercial" con el ejercicio de las letras trae aparejado que la escritura comienza a ser concebida como una profesión útil, tanto para el sujeto que la ejerce como para la sociedad que demanda los escritos.

Por otro lado, este cambio en la concepción del escritor tuvo notables repercusiones en el modo de relacionarse los intelectuales entre sí. En efecto, tal como ya se ha indicado, la rivalidad entre aquellos que se consideraban sabios tradicionales y los escritores más innovadores, más preocupados por la opinión de sus receptores que por el cultivo del saber a la manera de antaño, fue uno de los ingredientes fundamentales de la polémica de los literatos de la época.

En España, frente a los bríos que cobraban los nuevos hombres de letras, varios de los miembros más conservadores de la clase intelectual se vieron respaldados por la iniciativa estatal de fundar una Academia de Ciencias y Letras siguiendo el modelo de otras europeas. Se abría así otro medio para que el erudito pudiera vivir de las letras, pues se proponía pagarle un sueldo para que pudiera dedicarse exclusivamente al 
estudio $^{2}$. Con esto se afianzaban los lazos entre un sector de cultivadores del intelecto y el poder. Asimismo, las academias, como los otros tipos de instancias de reunión de intelectuales que proliferan en el Siglo de las Luces (las tertulias, los salones literarios o las Sociedades Económicas), constituyen una clara muestra de la apertura del pensador ilustrado a la sociedad y a la sociabilidad.

\section{LA ERUdición "A LA VIOLETA"}

He comentado que uno de los temas frecuentemente abordados por los ilustrados fue el de la erudición aparente. Encontramos así una nómina considerable de obras centradas en la denuncia de los charlatanes, de los sabios pedantes que se pavonean, de aquellos que repiten como papagayos, de los que se emparentan con los asnos por su necedad o de los petimetres que van como figurines de traje y peluca, pero que dedican poco tiempo al estudio. De este grupo de escritos abocados a la crítica de la falsa sabiduría, la obra española más importante y conocida es Los eruditos a la violeta (1772) de José de Cadalso. Este texto, que ofrece una sátira de "los que, sabiendo poco, aparentan mucha ciencia”, tiene el mérito añadido de haber acuñado el término erudito a la violeta -que luego con el uso se simplificará en la forma sustantivada violeto-, el cual se popularizó rápidamente y fue utilizado tanto por los autores cultos como también en las tonadillas del teatro popular escritas en los años inmediatamente posteriores. Como explica Cadalso, esta acertada denominación, escogida para su escuela burlesca de sabios hipócritas, se inspiró en el aroma a perfume de violetas que desprendía el típico intelectual de pacotilla que solía frecuentar los salones: el "erudito barbilampiño, peinado, empolvado, adonizado y lleno de aguas olorosas de lavanda, sanspareille, ámbar, jazmín, bergamota y violeta" (Cadalso 1967: 47)³. Este marbete se relaciona con otros que ya circulaban en la época como el de "eruditillos a la moda" utilizado por Nifo en la introducción de su Correo general histórico, literario y económico de Europa (1763); el de "semidoctos" presente en la aprobación que escribió el Padre Juan de Aravaca para las Memorias literarias de París (1751) de Luzán; el de "críticos a la cabriolé" propuesto por el Conde de Peñaflorida en Los aldeanos críticos (1758); o el de "semisabio" empleado por el Padre Isla en el ya mencionado Fray Gerundio.

Los eruditos a la violeta debe ser estudiada en relación con otras obras previas que abordan la temática de la falsa erudición; así, por ejemplo, La culta latiniparla (1624) o la sección "Para saber todas las ciencias y artes mecánicas y liberales en un día" del Libro de todas las cosas (1631) de Quevedo; o, ya en el siglo XVIII, De charlataneria eruditorum (1715) del alemán Mencke ${ }^{4}$, la Virtud al uso y mística a la moda. Destierro de la Hypocrisia... (c. 1729) de Fulgencio Afán de Ribera y Le philosophe soi-disant (1761) de Marmontel.

\footnotetext{
2 Para un estudio acerca de este aspecto económico vinculado al hombre de letras en el marco del reformismo borbónico, ver Álvarez Barrientos 1996.

3 Para la sátira del erudito (especialmente del letrado) en Cadalso y el Padre Isla ver Chen Sham, 2002.

4 Este texto, que tuvo influencia en el ámbito hispánico, circuló en una versión traducida por Forner en 1787 bajo el título Declamaciones contra la charlatanería de los eruditos (ver Álvarez Barrientos 1998). Fernández de Lizardi lo cita, por ejemplo, en El Periquillo Sarniento (164 y 771).
} 
Asimismo, Los eruditos a la violeta ha de vincularse con el género serio de libros de erudición universal que conoció una gran eclosión en el siglo ilustrado: enciclopedias, diccionarios, compendios del saber y tantas obras que parecían tener la receta para hacerse sabio sin mayor esfuerzo. Es el caso de dos textos que circulaban en la época: Erudición universal o análisis abreviado de todas las ciencias, buenas artes y bellas letras (1768) del Barón de Bielfeld y la Carta dirigida a un amigo en que se le da razón de las facultades y libros de que debe instruirse no sólo un poeta para el teatro, sino cualquiera que aspire a una erudición universal de Juan Manuel de Haedo $(1770,1772)^{5}$.

Tal como se adelanta en el subtítulo, Los eruditos a la violeta se ofrece a los lectores bajo la estructura, en clave satírica, de un Curso completo de todas las ciencias, dividido en siete lecciones, para los siete días de la semana. Cadalso afirma en la "Advertencia" que esta obrita pretende no solamente denunciar a los sabios fingidos, sino también avisar al resto de la sociedad para que en adelante valore con cautela la sabiduría ajena cuando ésta se muestre demasiado ampulosa.

El maestro de la academia burlesca de Cadalso propone entrenar a sus discípulos en el arte de saber fingir sabiduría reduciendo "a un sistema de siete días toda la erudición moderna”. Así, jornada a jornada les irá entregando valiosos consejos como que desechen "todo género de moderación con los iguales, toda clase de respeto a los mayores y toda especie de compasión a los inferiores"; que llenen sus "bien peinadas cabezas de párrafos de aquí y de allí" para poder citarlos a troche y moche; que lleven anteojos y que procuren pasar por distraídos, que se comporten con extravagancia, o que sean superficiales y extranjerizantes a ultranza.

Los eruditos a la violeta se completa con un suplemento (también publicado en 1772) en el que se citan las cartas de algunos discípulos aventajados, graduados en violetería, que han tenido éxito en sus engaños. Sin embargo, se muestra también que muchos de estos hipócritas fracasan al enfrentarse a personas serias y verdaderamente sabias.

La obra de Cadalso gozó de gran éxito en la época y a raíz de estas lecciones para falsos sabios surgieron varios escritos a modo de respuesta o continuación, como por ejemplo la Junta que en casa de don Santos Celis tuvieron ciertos eruditos a la violeta (noviembre de 1772) de Manuel Santos Rubín de Celis o el Comentario sobre el Doctor festivo y maestro de los Eruditos a la Violeta, para desengaño de los españoles que leen poco y malo (1773), firmado con el seudónimo de Pedro Fernández (Edwards 1976: 32-33). Un texto interesante que ofrece el revés serio de Los eruditos a la violeta es Los literatos en Cuaresma (1773), obra en la que Iriarte presenta a un grupo de seis amigos, juiciosos e instruidos, que disertan como auténticos sabios durante los seis domingos de Cuaresma. También resulta posible vincular la crítica de la erudición a la violeta cadalsiana con la dinámica de los eruditos aparentes habitual en las academias de conversación; en relación con esto, Sebold ha sugerido que la obra del gaditano podría estar parodiando una academia en particular, la que se reunía en Azcoitia a instancias del Conde de Peñaflorida (Sebold 1974: 242).

\footnotetext{
5 En la introducción de Glendinning a su edición de Los eruditos a la violeta y en Sebold 1974: 239-54 se aporta un completo panorama de las posibles fuentes e influencias relacionadas con Los eruditos a la violeta.
} 
Considerando lo expuesto, se puede afirmar que Los eruditos a la violeta aporta un matiz más en el retrato del nuevo hombre de letras de la Ilustración. En efecto, además de ser una sátira contra los aromáticos fantoches de salón, la obra de Cadalso demuestra que la falsa erudición fue una de las consecuencias del proceso de sociabilidad de la cultura, cuyos fundamentos fueron la conversación, el diálogo y la exteriorización del saber 6 .

\section{Saber y letras en el México ilustrado}

Una de las grandes preocupaciones de los miembros de la intelectualidad novohispana de la Ilustración será la de documentar la presencia de sabios en la historia de América, para afirmar la riqueza cultural del Nuevo Mundo frente a aquellos que la minusvaloraban desde el otro lado del Atlántico. Este intento de atestiguar el saber criollo ya había estado presente en el período anterior, fundamentalmente en la obra de Sigüenza y Góngora en obras como Teatro de virtudes políticas (1680), La Libra astronómica y filosófica (1690) o en el Triunfo Parténico (1683)7. La pieza más representativa de esta intención en la Nueva España dieciochesca es, sin duda, la Biblioteca Mexicana (1755) de Juan José Eguiara y Eguren, considerado el padre de la bibliografía mexicana ${ }^{8}$. Este catedrático de la Universidad de México se propuso la ingente tarea de elaborar, a partir de la revisión de librerías, historias, archivos de órdenes religiosas y de particulares, un catálogo biográfico de semblanzas de sabios novohispanos desde antes de la conquista hasta su presente. Tal como señala Eguiara y Eguren en los Anteloquia con los que abre su Biblioteca, esta gran empresa de recopilación estuvo motivada por los comentarios negativos que el filólogo español Manuel Martí Zaragoza ${ }^{9}$ había vertido acerca de la ignorancia generalizada en América y especialmente en México ${ }^{10}$.

6 Para un análisis de la desacralización de la cultura en Los eruditos a la violeta ver Álvarez Barrientos 1999.

7 Un completo análisis de estas obras de Sigüenza y Góngora en relación con el vínculo entre saber y afirmación de la identidad criolla es el de Lorente 1996.

8 Para mayores datos biográficos acerca de este autor, ver el estudio preliminar de Gómez de Orozco a su edición de Prólogos a la Biblioteca Mexicana y el trabajo de Torre Villar inserto en la compilación de trabajos de Eguiara y Eguren titulada Historia de sabios novohispanos. Estas dos obras se encuentran consignadas en la bibliografía final.

9 Esta polémica entre Eguiara y Martí ha sido estudiada por Rovira 1995. Eguiara y Eguren no fue el único que replicó a las ideas del deán alicantino acerca del estado de la cultura en Hispanoamérica. Podemos mencionar varios otros textos que también abordan esta cuestión: la Oratio apologetica (1745) de Gregorio de Campos y Martínez, el Aprilis dialogus -prólogo de la Biblioteca de Eguiara- de Vicente López, los planteamientos de Andrés de Arce y Miranda en el tomo III de sus Sermones (1760) o la Llave del Nuevo Mundo (1761) de José Martín Félix de Arrate (ver Rovira, 1995: 53-57).

10 En el siglo XVII encontramos una defensa de la sapiencia americana motivada por razones parecidas; me refiero a la Hypomnema apologeticum pro regali Academia Limensi in Lipsianum periodum (1647) escrita por el humanista criollo Diego de León Pinelo desde la Universidad de San Marcos de Lima como réplica correctora a la Bibliothecis Syntagma (1602) de Justo Lipsio, en la cual no se mencionaba ningún centro cultural del Nuevo Mundo. A finales del siglo XVIII, también en Perú, tiene lugar una polémica famosa relacionada con el tema de la capacidad intelectual de los americanos. Se trata de la respuesta de los mercuristas -los colaboradores habituales de El Mercurio peruano (1790-1795)- a los planteamientos de De Pauw acerca de la supuesta inferioridad del grado de civilización en América explicada por la crudeza del clima (teoría expuesta en Recherches philosophiques sur les Américains de 1771). En este 
De este modo, este comentario y la consecuente indignación que provocó en el erudito mexicano, conocedor y admirador de la cultura de su tierra, motivan la preparación de esta "historia de los varones eruditos" nacidos o ligados a la "América boreal”. Este compendio de las mentes más brillantes del México colonial incluye además referencias al México prehispánico. Para su elaboración, Eguiara y Eguren sigue un modelo textual precedente, el de otras "bibliotecas" anteriores como las de Nicolás Antonio, la Bibliotheca Hispana vetus (1672) y la Bibliotheca Hispana nova (1696).

En esta misma línea de defensa del valor de la sabiduría autóctona -específicamente la perteneciente a los pueblos originarios-, no puedo dejar de hacer una referencia a la labor de los jesuitas, los cuales, además de participar en este intento de afirmación de la cultura nacional, son miembros activos del humanismo ilustrado de América. Destaca en este contexto la labor de Francisco Javier Clavijero, acérrimo defensor de la capacidad intelectual de los americanos, que contribuyó en la refutación de las ideas muy difundidas en Europa de Buffon y De Pauw acerca de la degeneración de la naturaleza en América y la inferioridad de la inteligencia de los autóctonos del Nuevo Mundo con respecto a los europeos.

La Ilustración mexicana del ocaso del siglo XVIII no careció de destacados impulsores de la actividad letrada, los cuales, muchas veces, tuvieron que compatibilizar su tarea intelectual con otras lides relacionadas con el convulso momento independentista. Una de las figuras más prominentes dentro del panorama cultural mexicano del cambio de siglo fue, sin duda, Fray Manuel de Navarrete, poeta de profusa formación humanista, apodado por sus admiradores el "Cisne Americano" y que ha sido valorado como el principal poeta neoclásico de México. Fue el mayoral de la Arcadia Mexicana, el grupo literario más importante de finales de la etapa virreinal. Asimismo, sobresalen en el cultivo de las letras y en su difusión autores como Manuel Sartorio, presidente de la Academia de Humanidades; Anastasio de Ochoa y Acuña, latinista y traductor; José María Cos, fundador de El Ilustrador Americano; Andrés Quintana Roo, hombre de letras que se puso del lado de los insurgentes; o José María Lacunza, perteneciente a la Arcadia de México y luego fundador de la Academia de Letrán en 1836. Otra figura sin duda relevante dentro de este contexto cultural, que destaca por su labor de difusión del conocimiento, fue Carlos María Bustamante, fundador, junto con Jacobo de Villaurrutia, del Diario de México, primer cotidiano de la Nueva España.

Mas, sin lugar a dudas, quien constituye en la Nueva España de finales del XVIII y principios del XIX el fiel reflejo del nuevo hombre de letras que se había gestado durante la Ilustración es José Joaquín Fernández de Lizardi (México, 1776-1827), conocido como el Pensador Mexicano: intelectual atento al objetivo de informar, educar, entretener y criticar. Se desempeñó como periodista, novelista -famosa es su obra El Periquillo Sarniento (1816) valorada como la primera novela moderna hispanoamericana-, fue también dramaturgo y poeta ocasional, en suma, se desempeñó como un escritor de oficio que vivió de y para su pluma.

contexto destaca el naturalista criollo José Hipólito Unanue, quien contradice las ideas del abate en su obra Observaciones sobre el clima de Lima y sus influencias en los seres organizados, en especial el hombre (Lima, 1806; reeditado en Madrid, 1815). Ver Clément 1997: 249-251. 
Sus obras literarias y sus producciones periodísticas se inscriben en el marco de una escritura ilustrada y patriótica con miras a la formación de ciudadanos de pro, de dignos representantes políticos, de ejemplares padres de familia, y también de mentores de las letras y el saber. A continuación revisaré una serie de matizaciones que este autor aporta con respecto a la noción de saber y especialmente en relación con la sabiduría en México.

Una de las constantes en la obra lizardiana es la reflexión acerca de la noción de sabiduría $^{11}$. Encontramos así abundantes referencias en sus escritos al quehacer del verdadero sabio frente a los falsos eruditos. Estos planteamientos deben contextualizarse en el marco del debate ilustrado acerca del saber y sus agentes que hemos esbozado con anterioridad. En efecto, se observan estrechos vínculos entre el pensamiento lizardiano y las propuestas de autores españoles como Feijoo, Cadalso, Forner, Iriarte... En el caso de Lizardi, las reflexiones en torno a la noción de sabiduría han de relacionarse con la situación de una Nueva España que prontamente se iba a convertir en nación independiente, con lo cual en varios pasajes de los textos del mexicano la reflexión acerca de la sabiduría se emparentará con la idea de americanidad.

\section{DE CURRUTACOS, VIOLETOS Y CHARLATANES}

Fernández de Lizardi, enemigo acérrimo de la falsa erudición, criticó las reuniones de sociedad que se congregaban supuestamente con fines culturales, pero que en el fondo no eran otra cosa que excusas para la diversión superficial. Así, en un artículo de Alacena de Frioleras titulado "Sociedades públicas", compara las sociedades patrióticas, económicas y de amigos del país de la culta Europa, cuyos loables fines, según el periodista, eran "fomentar la industria y agricultura, o bien de adelantar o ilustrar en las ciencias a la juventud", con las "casas de sociedad" mexicanas, cuyo fin principal era divertirse a costa del prójimo:

Y digo ahora: ¿nuestras decantadas sociedades podrán darnos algún provecho? Examinemos ligeramente lo que son; mas ¿qué tenemos que examinar, cuando sabemos que no son más que unos garitos, o casas (por honrarlos), donde se come, se bebe (y no agua), se juega y se platican impertinencias cuando menos? Éstas son nuestras casas de sociedad, que mejor se debían llamar de ociosidad. [...] Ya que nuestra desgracia no nos proporciona casas de verdaderas sociedades patrióticas donde se discuta y proyecte sobre la felicidad del pueblo, no tengan la osadía las casas donde se pela al próximo de usurpar un nombre que no les toca. Llámense casas públicas de diversión y quedaremos los coimes y yo amigos usque ad aras (1970: 96-97).

Tal como describe González Obregón en su célebre México en 1810, la "fauna" que solía acudir a los cafés y tertulias era heterogénea; no obstante, los frecuentaban con mayor asiduidad unos "especímenes" en particular, los conocidos como recetantes, planchados, currutacos o manojitos (1943: 57-72)12: variantes de los petimetres,

\footnotetext{
11 Este aspecto de la obra lizardiana lo he abordado en Insúa 2009.

12 Cabe aclarar que los términos currutaco o pirraca eran también utilizados en la España de la Ilustración para denominar al petimetre o petimetra. Abundan los textos en los que se hace sátira de este tipo social bajo esas denominaciones; es el caso de la escena unipersonal titulada Don Líquido, o el currutaco vistiéndose
} 
cercanos en su vacua altanería a los ya mencionados eruditos a la violeta, que también invadían los centros sociales mexicanos de aquel entonces. Este tipo del falso señorito que vive fingiendo alcurnia y sabiduría -y su versión femenina, la currutaca, pirraquita o madama- fue frecuentemente criticado en sermones, discursos y artículos de prensa y abordado con sorna en la poesía burlesca novohispana ${ }^{13}$. Veamos, por ejemplo, el romancillo de un poeta festivo que se hacía llamar «El Chulito Flégile Pávea», publicado en el Diario de México del 16 de febrero de 1810, en el que se aborda satíricamente el comportamiento aparentoso de estos currutacos:

\author{
En México viven \\ ciertos hombrecillos; \\ con perdón de ustedes \\ voy a describirlos. \\ Ellos son muy pobres, \\ no tienen destino \\ ni colocación; \\ pero son tan vivos \\ que pasan la vida \\ de ajeno bolsillo. \\ Ellos se levantan \\ rabiando de frío, \\ de su como-cama, \\ de haber mal dormido; \\ a ponerse empiezan \\ su como-vestido, \\ que consta de piezas \\ que a otros han servido; \\ y después acuden \\ a un como-lebrillo, \\ que tienen con agua \\ siempre prevenido; \\ $\mathrm{y}$ haciendo mil gestos, \\ por causa del frío, \\ se lavan el rostro, \\ y con un cepillo \\ cruelmente se estregan
}

(Valencia, Imprenta de Estevan, 1813) de Juan Jacinto Rodríguez Calderón; de El currutaco de Sevilla: romance nuevo en el que se declara el más gracioso chasco que le sucedió a un currutaco con un estudiante, pues pensando jeringarlo el currutaco, fue el currutaco jeringado por el estudiante... (anterior a 1816); o del Libro de moda en la feria, que contiene un ensayo de la historia de los currutacos, pirracas y madamitas del nuevo cuño y los elementos o primeras nociones de la ciencia currutaca (Valencia, Imprenta del Diario, 1795) de Juan Fernández de Rojas.

13 Se ha documentado la publicación de varias sátiras periodísticas dirigidas contra el tipo del currutaco en los periódicos de la época, especialmente en el Diario de México; ver Wold 1970: 121-124, y también Martínez Luna 2005: 49-51. En cuanto al tratamiento satírico-burlesco del tipo del presumido ridículo en el México de la Ilustración, cabe mencionar una curiosa composición satírica en verso, El currutaco por alambique (México, Mariano Josep de Zúñiga y Ontiveros, 1799) de Manuel Gómez Marín, estudiado recientemente por López Mariscal 2009. Este texto tuvo cierta resonancia hasta bien entrado el siglo XIX, prueba de lo cual es la publicación de un calendario con el mismo motivo: Calendario del currutaco por alambique: arreglado al meridiano de México a cargo de M. Muñoz y Orta (México, Imprenta de Tomás S. Gardida, 1854). 
entrambos carrillos, y queda aquel cutis, que antes tan pajizo por el hambre estaba, de buen colorido.

Van al como-espejo, que es tan reducido, que no cabe un ojo, para en él ser visto.

Cuando ven que están muy cari-raídos, salen a la calle con aspecto altivo; se entran a un café, y entre los corrillos de conversación se introducen finos: en todo dan voto, como hombres instruidos en todas materias.

Si hay algún amigo que ofrezca café, chocolate hervido, ponche, té o alguna cosa de lo mismo, que en la casa venden, luego es admitido el convite, y comen que es bello prodigio, como que es de coca... Mas si el cruel destino niega este socorro, ¡pobres manojitos! Se van al Portal, pasan el martirio de ver tanto bueno como allí advertimos: clavan en la fruta los ojos hundidos; si hallan quien ofrezca queso, fruta, vino, etcétera... admiten al instante mismo; mas si esto no encuentran, ipobres manojitos!

No dejan café, fonda, bailecillo, donde no se metan por ser socorridos... ¡Pobres recetantes, pobres manojitos! (Cit. en González Obregón 1943: 69-72) 
Dentro de la sátira del tipo del currutaco es habitual la referencia a su aspecto "afeminado" conseguido merced al uso de afeites, fragancias (al estilo de los violetos), accesorios como aretes, prendedores y abanicos, y sobre todo, por llevar peinados mujeriles y vestir trajes extravagantes (generalmente formados con retazos, al modo de los que se componían los hidalgos chanflones del Buscón quevediano). Otros modales currutacos que se solía ridiculizar eran los manoteos y dejes afectados al hablar, de los que estos señorones se valían para alardear de sabiduría. Así lo expresa un poeta anónimo novohispano en una composición en la que el hablante se burla, entre otras cosas, de los ademanes exagerados del petimetre:

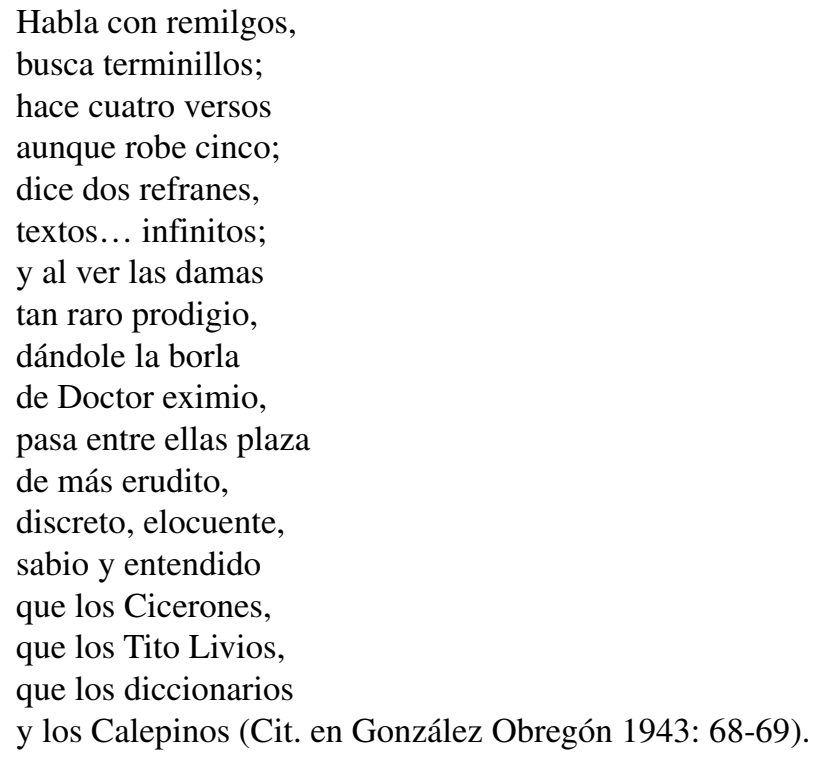

\section{LA CRÍTICA A LA FALSA ERUDICIÓN Y A LA ELEGANCIA FINGIDA EN LA OBRA LIZARDIANA}

Fernández de Lizardi, fiel a su objetivo de educar a la sociedad mediante la crítica de los vicios que la afectan, incorpora en sus producciones periodísticas y literarias referencias a los petimetres y también a los falsos sabios. De este modo, por ejemplo en "Los paseos de la Verdad"14 -un conjunto de artículos en los que inscribe la sátira en el marco ficcional de un sueño-, Lizardi menciona, dentro de la galería de tipos sociales a los que critica, a unos "intelectualoides" reunidos en el Portal de Mercaderes -"topadero de los sabios, de los juiciosos, presumidos, ignorantes y charlatanes"-que participan sin fundamento alguno en una discusión acerca del valor de los trabajos del mismo Pensador Mexicano. Tal es el caso de un "currucacho" que, cual violeto consumado, reprueba los artículos lizardianos por insulsos y carentes de florilegios retóricos:

14 Publicados en Alacena de Frioleras, núms. 18-22. 


\begin{abstract}
Nada dice que no esté dicho, y fuera de esto, su estilo es un estilo de bodegón. Metáforas, alegorías, tropos, bellezas, flores de elegancia, ni las conoce. Erudición selecta, ni la ha visto. Noticias exquisitas, no las tiene. Términos castizos, exóticos y retumbantes, ni los sabe. Sólo nos emboca moralidades añejas, sátiras frías y cuentos de cocina, y esto con una cantinela monótona y nevada. Lo único que tiene es lo que más enfada, y es aquel estilo faceto, truhán y chocarrero con que sin tener sal quiere las más veces arrancar la risa a sus miserables lectores (Fernández de Lizardi 1970: 118).
\end{abstract}

Como podemos apreciar, Lizardi, a través de la incorporación de este pasaje en boca de un "caballerazo" parlanchín, nos entrega una síntesis de los recursos ampulosos que utilizaban los violetos para captar la atención de sus receptores. Además, el Pensador, mediante esta descripción ex contrario inscrita en el molde satírico, ofrece una valoración del estilo de la sencillez, ponderado por él como el medio más eficaz para educar al pueblo.

El tema de la falsa sabiduría es abordado en distintos pasajes de los papeles periódicos lizardianos. Así, en un artículo de El Pensador Mexicano, "Secretos útiles y eficaces para muchas personas, hallados en la cartera del Gran Turco", Lizardi no olvida dedicar un par de máximas a esta cuestión: "El que quiera parecer sabio entre los necios, que hable mucho. El que quiera parecer discreto entre los sabios, que hable poco" (1968: 203). En otro artículo de este mismo periódico, "Concluye mi vindicación", se defiende frente a los que lo atacan por criticar las falencias de la sociedad mexicana, y se refiere a sus detractores -el periodista apodado Nugagá y sus aliados- diciendo que sus letras son de facistol (de atril) y sus licenciaturas "accidentales", y concluye declarando que el comportamiento de estos ignorantes le ha hecho darse cuenta de que en su patria "hay mucho vulgo entre bonetes y capas de golilla"(1968: 449). Esta última referencia al vestido que encubre la falsa erudición se puede relacionar con la propuesta de Lizardi inserta en su burlesca "Pragmática, bando o quién sabe qué, mandado publicar por la Razón, el Tiempo y la Experiencia", publicada en Alacena de Frioleras, en la que se sugiere que los verdaderos sabios que han sufrido "gajes, propinas, estudios y desvelos" salgan a la calle con sus borlas y capelos puestos para distinguirse de los falsos doctos (1970: 162).

Por otro lado, en sus poemas de tono satírico en los que se presenta una galería de tipos sociales con sus correspondientes vicios, el falso erudito y el currutaco suelen estar siempre consignados. Así sucede en «Ninguno diga quién es, que sus obras lo dirán», composición en la que el yo lírico promete desvelar los disfraces que muchos usan sin ser Carnaval, hace hablar a las máscaras del que se pretende sabio:

\footnotetext{
MÁSCARA 2. ${ }^{\mathrm{a}}$

Con un vestido brillante

y un hablar desenfadado

se presenta enmascarado

por sabio algún ignorante.

Y aun en la conversación

que no entiende palotada, habla mucho y dice nada, por sostener su opinión; pero por más que se esponje
} 
por pasar por entendido,

todos tienen bien sabido

que el hábito no hace al monje.

Y mas que le dé coraje,

yo le diré que es más necio

si cree se le debe aprecio

por la apariencia del traje (1963: 90-91).

Destacan también en este conjunto de textos algunas fábulas en verso en las que el Pensador se vale de locutores animalescos para criticar la falsa sabiduría y los ademanes afectados. Así, en "El mono y el perico", publicada en Alacena de Frioleras (1970: 67-71), se ridiculizan las "monerías" que muchas veces realizan los hombres para mostrarse elegantes, a través de la historia de un mono que quiere parecerse a ellos y termina por convertirse en un "currutaco andante". El comportamiento pedantesco de aquellos que tratan de aparentar lo que no son también es criticado en la fábula "El mono vano" (1963: 370-71), en la que un mico presumido intenta sin éxito esconder su cola debajo de vestidos humanos, con lo que el relato denuncia su condición de absurdo imitador. En otra fábula titulada "El loro en la tertulia" (1963: 365-67)15, el perico -animal que ocupa junto con el mono y el asno un lugar destacado en la sátira de la sabiduría aparente- se muestra esta vez en una reunión de animales ante los cuales alardea parlanchín de un saber del que ciertamente carece.

También en la obra narrativa de Fernández de Lizardi, tanto en las digresiones del narrador como en los diálogos entre los personajes, aparecen abundantes referencias al tema de la falsa erudición. Por ejemplo, en El Periquillo Sarniento, cuando el protagonista se encuentra en la exótica isla de Saucheofú ${ }^{16}$, uno de los diálogos con Limahotón -el hermano del tután que le explica la organización de esta sociedad ideal- versa acerca de los pedantes que presumen de sabios "disparando latinajos de cuando en cuando". Periquillo le comenta al "chino" que en su tierra los eruditos salpican de latines su conversación para que los tengan por instruidos. A Limahotón le llama la atención esta costumbre y dice que en su isla nunca se tendrá por sabio aquel cuyo discurso resulte incomprensible, "pues la gracia del sabio está en darse a entender a cuantos lo escuchen" (1997: 771).

En la obra lizardiana, el tema de la erudición aparente en versión femenina tiene, por supuesto, en Pomposita, la protagonista de La Quijotita y su prima, su ejemplo más consumado. Esta joven, además de ser una coqueta currutaca, presume de sabihondilla. De hecho, la educación de esta joven, a cargo de una madre consentidora y un padre sin carácter, pecó, entre otros defectos, de celebrar las gracias "seudointelectuales" de la moza, desde muy pequeña; razón que la llevó a convertirse, en palabras del coronel, padre de la virtuosa Pudenciana, en una "erudita a la violeta y bachillera perdurable" que, tal como se percata el narrador, se expresa en un estilo "ampolludo y pedantesco" (1980: 202-3).

\footnotetext{
15 Una interesante aproximación a las fábulas lizardianas desde la perspectiva de la sátira y la emblemática la aporta Oviedo y Pérez de Tudela 2009.

16 Para un análisis de este episodio ver Knowlton 1963, Joset 1986, Sainz de Medrano 1987, Alba-Koch 1999: 159 y ss., e Insúa 2008: 122-26.
} 
Mas, sin duda, el personaje lizardiano que mejor encarna el comportamiento basado en la mera apariencia es don Catrín de la Fachenda, protagonista de la novela homónima, un personajillo con ansias de nobleza cuyo único objetivo vital es conseguir con industria -y no con el trabajo honrado- el estatus social que no tiene por origen. En efecto, su vida está orientada a aparentar lo que no es y para conseguirlo cualquier argucia es válida. En efecto, don Catrín, como los currutacos y los violetos, vive preocupado por ostentar en el vestir y en el discursear. Aunque, según bien sabemos, su sapiencia y sus atuendos son pura "facha". Sirva como muestra de esta actitud la atinada definición de este tipo social puesta en boca del viejo con el que don Catrín discute acerca de la vida catrinesca en un café:

... el catrín es una paradoja indefinible, porque es caballero sin honor, rico sin renta, pobre sin hambre, enamorado sin dama, valiente sin enemigo, sabio sin libros, cristiano sin religión y tuno a toda prueba (2001: 113).

\section{PARA CONCluir: El PERIODista COMO NUEVO HOMBRE DE LETRAS}

En la nueva concepción de hombre de letras que se gesta en la Ilustración y que se relaciona con la incorporación de nuevos sujetos a la República literaria, destaca especialmente la figura del periodista, confundido en ocasiones por los académicos más rancios con el erudito superficial o con el sabio simplón que quería captar la atención del público lector. Fernández de Lizardi procura demostrar en sus escritos la diferencia que existe entre esos violetos criticados y satirizados y el buen periodista comprometido con la causa patriótica y maestro del pueblo ${ }^{17}$.

Este naciente modelo de periodista que educa, sabe que su palabra ha de llegar a otros hombres de letras pero también a toda la población. Nos encontraremos así con numerosas declaraciones de articulistas de la época que afirman su intención de ser claros en el discurso. El Pensador Mexicano fue un paladín del decir sin ambigüedades, abierto a todo aquel que quisiera leer sus trabajos, sin importar su condición. Además, cabe destacar que el periodismo de este período, linguíisticamente hablando, se abre a la ciudadanía a través de una nueva manera de expresión del mundo letrado, al dar cabida en la escritura a expresiones populares, de marcada oralidad y tono familiar ${ }^{18}$. En esto también Lizardi se encuentra a la cabeza; baste recordar sus artículos escritos en forma dialógica que aparecen jalonados por diversos modos del habla popular, entre los que destacan sin duda las célebres Conversaciones del Payo y el Sacristán.

Las referencias a la actividad del escritor periódico constituyen uno de los ejes centrales de la obra de prensa de Fernández de Lizardi. Este constante reflexionar acerca de la propia labor responde al interés del periodista por consolidarse como sujeto recién arribado a la República literaria.

Fernández de Lizardi, ya en la misma elección del título de su principal periódico, pone de manifiesto cuál ha de ser su función como agente informador y crítico. La posterior adopción de ese título como seudónimo pone aún más en evidencia que el

\footnotetext{
17 Para una síntesis de la relación del periodista y la sociedad en la obra lizardiana ver Insúa 2010.

18 Pueden verse más detalles acerca del debate de cuestiones lingüísticas y ortográficas en la prensa mexicana del período en Vogeley 2001: 34-45.
} 
mexicano se considera por sobre todo un "pensador". Un pensador-periodista del estilo de otro que también fue llamado como su periódico: José Clavijo y Fajardo. De este modo, los artículos lizardianos se muestran en la misma línea del Pensador español, quien a su vez era continuador del estilo del The Tatler y The Spectator ingleses. Por ello, Lizardi puede ser valorado como un eslabón americano en la cadena de un modo de escritura periodística caracterizada por la observación atenta de la sociedad, cuyo fin central era poder aportar útilmente a su funcionamiento. Aportación que debía hacerse, tal como señala Jean Franco, desde la mirada ilustrada, a partir del ideal de una comunicación clara, es decir, que unívocamente pudiera transmitir lo racional y lo verdadero (1983: 4-5).

\section{OBRAS CITADAS}

Alba-Koch, Beatriz de. 1999. Ilustrando la Nueva España: Texto e imagen en «El Periquillo Sarniento» de Fernández de Lizardi. Cáceres: Universidad de Extremadura.

Álvarez Barrientos, Joaquín. 1989. "El hombre de letras español en el siglo XVIII”, en Actas del Congreso Internacional sobre "Carlos III y la Ilustración". Madrid: Ministerio de Cultura. 417-26.

—. 1992. "La figura del escritor en el siglo XVIII". Cuadernos de Ilustración y Romanticismo 2: $13-29$.

- 1993. "Cuando las letras llegaron a ser 'de cambio': sobre la República literaria española en el siglo XVIII", en De místicos y mágicos, clásicos y románticos. Ed. A. Calderone. Messina: Armando Siciliano. 33-46.

—. 1995. "Los hombres de letras", en La República de las Letras en la España del siglo XVIII. Ed. Joaquín Álvarez Barrientos, François López e Inmaculada Urzainqui. Madrid: CSIC. 19-61.

—. 1996. "La profesión de escritor ante el reformismo borbónico", en El reformismo borbónico. Ed. A. Guimerá. Madrid: Alianza. 227-46.

—. 1998. "Forner traduce a Mencke: las Declamaciones contra la charlatanería de los eruditos (1787)", en Juan Pablo Forner y su época (1756-1797). Ed. Jesús Cañas Murillo y Miguel Ángel Lama. Mérida: Editora Regional de Extremadura. 567-83.

-. 1999. "El violeto de Cadalso como bel esprit", en Ideas en sus paisajes: homenaje al profesor Russell P. Sebold. Coord. Guillermo Carnero, Ignacio Javier López y Enrique Rubio. Alicante: Universidad de Alicante. 43-62.

Cadalso, José. 1967. Los eruditos a la violeta. Introducción de Nigel Glendinning. Salamanca: Anaya.

—. 2002. Cartas marruecas. Noches lúgubres. Ed. Rusell P. Sebold, Madrid: Cátedra.

Clément, Jean Pierre. 1997. El Mercurio Peruano (1790-1795). Estudio y antología. Madrid/ Frankfurt am Main: Iberoamericana/Vervuert. 2 vols.

Chartier, Roger. 1995. "El hombre de letras", en El hombre de la Ilustración. Ed. Michel Vovelle. Trad. José Luis Gil Aristu. Madrid: Alianza. 153-95.

Chen Sham, Jorge. 2002. "La sátira del letrado en el siglo XVIII español: ¿cliché o sociotipo”. Dieciocho 25.2: 229-42.

Edwards, June K. 1976. Tres imágenes de José Cadalso: El crítico. El moralista. El creador. Sevilla: Universidad de Sevilla.

Eguiara y Eguren, Juan José de. 1998. Historia de sabios novohispanos. Ed. Ernesto de la Torre Villar. Trad. Benjamín Fernández Valenzuela y Salvador Díaz Cíntora, México: Universidad Nacional Autónoma de México. 
—. 1984. Prólogos a la Biblioteca Mexicana. Trad. Agustín Millares Carlo. México: Fondo de Cultura Económica.

Feijoo, Benito Jerónimo de. 1863a. "Sabiduría aparente", en Obras escogidas. Madrid: Rivadeneyra. 77-81.

-. 1863b. "Dictado de las aulas", en Obras escogidas. Madrid: Rivadeneyra. 438-41.

—. 1986. "El gran magisterio de la experiencia", en Teatro crítico universal. Ed. y selección Giovanni Stiffoni. Madrid: Castalia. 332-35.

Fernández de Lizardi, José Joaquín. 1963. Obras I. Poesía y fábulas. Ed. Jacobo Chencinsky y Luis Schneider, México: Universidad Nacional Autónoma de México.

—. 1968. Obras III. Periódicos. El Pensador Mexicano. Ed. María Rosa Palazón y Jacobo Chencinsky. México: Universidad Nacional Autónoma de México.

-. 1970. Obras IV. Periódicos. Alacena de Frioleras, Cajoncitos de la Alacena, Las Sombras de Heráclito y Demócrito, El Conductor Eléctrico. Ed. María Rosa Palazón. México: Universidad Nacional Autónoma de México.

—. 1980. Obras VII. Novelas. La educación de las mujeres o La Quijotita y su prima. Vida y hechos del famoso caballero don Catrín de la Fachenda, Ed. María Rosa Palazón. México: Universidad Nacional Autónoma de México.

—. 1997. El Periquillo Sarniento. Ed. Carmen Ruiz Barrionuevo. Madrid: Cátedra.

-. 2001. Don Catrín de la Fachenda. Noches tristes y día alegre. Ed. Rocío Oviedo y Almudena Mejías. Madrid: Cátedra.

Franco, Jean. 1983. "La heterogeneidad peligrosa: escritura y control social en vísperas de la independencia mexicana”. Hispamérica 34-35: 3-34.

González Obregón, Luis. 1943. México en 1810. México: Stylo.

Insúa, Mariela. 2008. "Aventura y rebeldía en El Periquillo Sarniento de Fernández de Lizardi”, en Rebeldes y aventureros: del Viejo al Nuevo Mundo. Ed. Hugo R. Cortés, Eduardo Godoy y Mariela Insúa. Pamplona/Madrid/Frankfurt am Main: Universidad de Navarra/ Iberoamericana/Vervuert. 115-31.

—. 2009. "Una aproximación al tema de la sabiduría en la obra de José Joaquín Fernández de Lizardi”, en Anais do V Congresso Brasileiro de Hispanistas / I Congresso Internacional da Associaçao Brasileira de Hispanistas. Ed. Sara Rojo y otros. Belo Horizonte: Faculdade de Letras da UFMG, 1657-64. Disponible en http://www.letras.ufmg.br/espanhol/Anais/ index.htm

—. 2010. "Periodismo y sociedad en la Nueva España de la Ilustración: José Joaquín Fernández de Lizardi”, en Textos sin fronteras. Estudios sobre Literatura y sociedad. Ed. Tapsir Ba, Álvaro Baráibar, Ruth Fine y Carlos Mata. Pamplona; Eunsa, 2010, 151-63.

Joset, Jacques. 1986. "La utopía degradada de J. J. Fernández de Lizardi”, en Homenaje a Pedro Sainz Rodríguez. Tomo 4. Madrid: Fundación Universitaria Española. 439-48.

Knowlton, Edgar C. 1963. "China and the Philippines in El Periquillo Sarniento". Hispanic Review 31.4: 336-47.

López Mariscal, Blanca. 2009. “El currutaco por alambique de Manuel Gómez Marín. Un texto satírico del siglo XVIII", en Poesía satírica y burlesca en la Hispanoamérica colonial. Ed. Ignacio Arellano y Antonio Lorente Medina. Pamplona/Madrid/Frankfurt am Main: Universidad de Navarra/Iberoamericana/Vervuert. 239-52.

Lorente Medina, Antonio. 1996. La prosa de Sigüenza y Góngora y la formación de la conciencia criolla mexicana. México: Fondo de Cultura Económica.

Martínez Luna, Esther. 2005. "Diario de México: ilustrar a la plebe", en La República de las Letras. Asomos a la cultura escrita del México decimonónico. Vol. II, Publicaciones periódicas y otros impresos. Ed. Belem Clark de Lara y Elisa Speckman Guerra. México: Universidad Nacional Autónoma de México. 43-55. 
Montesquieu, Charles de Secondat, barón de. 2000. Cartas persas. Ed. Josep M. Colomer. Trad. José Marchena. Madrid: Alianza.

Oviedo y Pérez de Tudela, Rocío, 1982. La obra de Joaquín Fernández de Lizardi. Prosa periodística. Tesis doctoral inédita. Madrid: Universidad Complutense.

—. 2009. "Sátira y emblema. Recursos del pensamiento crítico criollo", en Poesía satírica y burlesca en la Hispanoamérica colonial. Ed. Ignacio Arellano y Antonio Lorente Medina Pamplona/Madrid/Frankfurt am Main: Universidad de Navarra/Iberoamericana/Vervuert. 323-349.

Rovira, José Carlos. 1995. "Para una revisión de la polémica mexicana dieciochesca con Manuel Martí, deán de Alicante", en Entre dos culturas. Voces de identidad hispanoamericana. Alicante: Universidad de Alicante, 45-62.

Sainz de Medrano, Luis. 1987. "La utopía en El Periquillo Sarniento". Dicenda. Cuadernos de Filología Hispánica 6: 509-23.

Sebold, Rusell P. 1974. Cadalso: el primer romántico 'europeo' de España. Madrid: Gredos.

Vogeley, Nancy. 2001. Lizardi and the Birth of the Novel in Spanish America. Gainesville: University Press of Florida.

Wold, Ruth. 1970. El Diario de México. Primer cotidiano de Nueva España. Madrid: Gredos. 
